\title{
Adiabatic Shear in Ordnance Components and Threaded Connections
}

\author{
F.E. Schmidt ${ }^{1}$, M.A. Hineman ${ }^{1}$, and J.D. Fuerst ${ }^{1}$ \\ ${ }^{1}$ Engineering Systems Inc., Aurora, IL
}

Adiabatic shear bands in steel are sometimes referred to as "white martensite". These bands are a unique and definitive indication of dynamic high speed deformation. Often the location, intensity and thin lathe (shear band) geometry make it difficult to confirm by $\mathrm{x}$-ray diffraction or micro-hardness testing. Even with light non-standard micro-hardness test loads, detection is an insidious aspect except that explosive forces are necessary. Therefore, metallography is from a practical perspective the most powerful evaluation method to determine the effect. Extreme care in sample preparation and etching must be exercised. In this matter EDS analysis verified the white bands were not from the mating stainless steel components. The adiabatic effect occurs in one dynamic event, not to be confused with impact fatigue [1], a progressive failure [2]. The following examples were documented from ordnance components. Adiabatic effects occur most often by abusive pressures (5 times the factory test pressures) or severe obstruction in shotgun locking notch areas. The notch is observed to be upset and deformed. A cross section through the notch indicates a crescent shaped adiabatic shear band. In 70-30 brass cartridges, the classic wedge shear band has been characterized in $5.56 \mathrm{~mm}$ high speed SCAMP (Small Caliber Ammunition Manufacturing Process) products, as a rare but significant longitudinal failure mode in ballistic testing [3]. This matter involves threaded joints in steel where the forces are explosively high.

The allegation in these joint failures is that the shape, size or metal working has been performed improperly. Figure 1 shows a 14 thread inside diameter profile from rifling (narrow) end to the wider breech end. The same consideration exists for screw-in barrels/receiver configuration, Knoop micro-hardness measurements were made at a fixed distance below all 14 thread roots. Figures 2 - 4 show the microstructural profiles. Table 1 indicated two independent test labs reported a uniform hardness and Figures $5-7$ illustrate the white martensite phase.

The identification of intense "adiabatic" shear bands was found across the three visual and wear debris topographical inside diameter surfaces. The etchant used was $2 \% \mathrm{Nital}$ with the testing repeated twice by grinding back the cross sectional profile. Figures 5 - 7 illustrate the "white martensitic" layer observed in all three regions of the threaded connection failure.

Threaded connections that experience dynamic explosive strain rates can exhibit adiabatic shear bands if the intensity and localization of the shearing forces reach the threshold concentration to induce dynamic shear. The formation of "white martensite", while difficult to identify is conclusive and was not the result of metal transfer from the adjacent stainless steel.

\section{References:}

[1] F.E. Schmidt, Jr., and D. M. Norfleet, "Impact Fatigue Failure of Ordnance Components", M \& M, IMS Proceedings, July 2009. 
[2] F.E. Schmidt, Jr., et al, "Failure Analysis of Firearm and Ammunition Components", M \& M, IMS Proceedings, July 2005.

[3] Frederick Schmidt, Jr., "Optimization of the Formability of 70:30 Brass and the Elimination of the Wedge Defect in Cartridge Cases", PhD. Dissertation, Drexel University, December 1995.

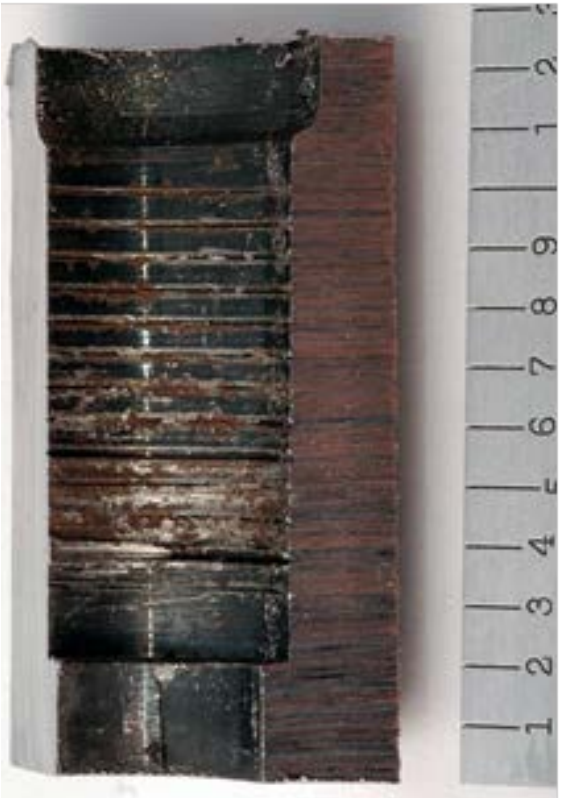

Figure 1: Section of threaded steel region with threads 1-14, top to bottom.

\begin{tabular}{|l|l|l|}
\hline \multirow{3}{*}{ Thread } & \multicolumn{2}{|l|}{ Hardness Below Thread Root } \\
\cline { 2 - 3 } & As Received & After Grinding \\
\cline { 2 - 3 } & HK 500 & HK$_{500}$ \\
\hline 1 & 228 & 222 \\
\hline 2 & 222 & 215 \\
\hline 3 & 222 & 223 \\
\hline 4 & 223 & 220 \\
\hline 5 & 228 & 218 \\
\hline 6 & 220 & 215 \\
\hline 7 & 223 & 223 \\
\hline 8 & 218 & 218 \\
\hline 9 & 216 & 215 \\
\hline 10 & 214 & 210 \\
\hline 11 & 211 & 223 \\
\hline 12 & 223 & 221 \\
\hline 13 & 214 & 223 \\
\hline 14 & 215 & 211 \\
\hline
\end{tabular}

Table 1: Microhardness test results
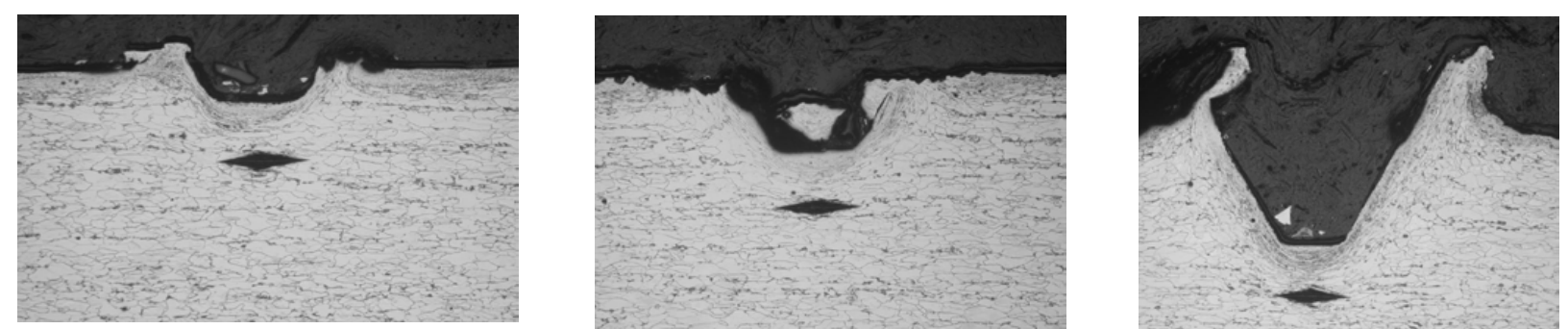

Figures 2 - 4: Cross sections of profiles of threads \#3, \#8, and \#14 (original magnification 100x).
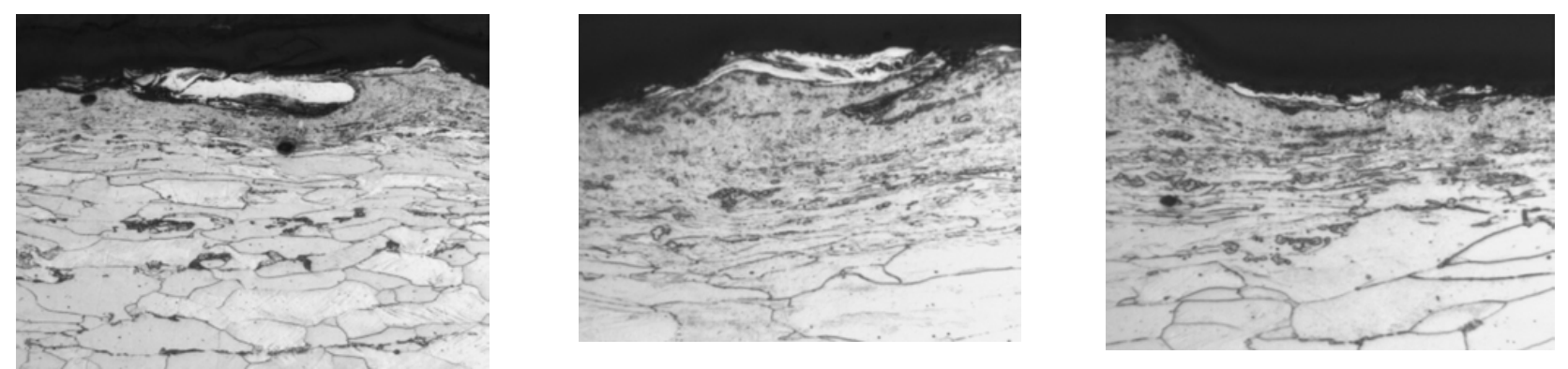

Figures 5 - 7: Cross sections showing white adiabatic shear regions as white areas near the surface at original magnifications of $400 \mathrm{X}$ (left) and 1000X (center and right) between thread locations 13-12, 1110 , and 10-9, respectively. 